\title{
The Use of a Staged Drainage Seton for the Treatment of Anal Fistulae or Fistulous Abscesses
}

\author{
Cheong Ho Lim, Hyeon Keun Shin, Wook Ho Kang, Chan Ho Park, Sa Min Hong, Seung Kyu Jeong, \\ June Young Kim, Hyung Kyu Yang \\ Department of Coloproctology, Yang Hospital, Seoul, Korea
}

Purpose: The aim of this retrospective study was to evaluate the rate of recurrence and incontinence after the treatment of fistulae or fistulous abscesses by using the staged drainage seton method.

Methods: According to the condition, a drainage seton alone or a drainage seton combined with internal opening (IO) closure and relocation of the seton was used. After a period of time, the seton was changed with 3-0 nylon; then, after another period of time, the authors terminated the treatment by removing the 3-0 nylon. Telephone interviews were used for follow-up. The following were evaluated: the relationship between the type of fistula and recurrence; the relationship between the type of fistula and the period of treatment; the relationship between the recurrence and presence of abscess; the relationship between IO closure and recurrence; the relationship between the period of seton change and recurrence; reported continence for flatus, liquid stool, and solid stool.

Results: The recurrence rate of fistulae or suppuration was 6.5\%, but for cases of horseshoe extension, the recurrence rate was $57.1 \%$. The rate of recurrence was related to the type of fistula $(P=0.001)$. Incontinence developed in $3.8 \%$ of the cases. No statistically significant relationship was found between the rate of recurrence and the presence of an abscess or between the closure of the IO and the period of seton change or removal.

Conclusion: In the treatment of anal fistulae or fistulous abscesses, the use of a staged drainage seton can reduce the rate of recurrence and incontinence.

Keywords: Seton; Surgical drainage; Fistula; Perianal abscess

\section{INTRODUCTION}

Many methods have been proposed for the treatment of an anal fistula with or without anorectal suppuration [1-5]; however, an aggressive approach is known to result in a decreased rate of recurrence but an increased risk of postoperative functional complications. In addition, overly vigorous treatment may distort the anatomy and impair incontinence. Decreasing the rate of recurrence

Received: August 29, 2012 - Accepted: December 19, 2012

Correspondence to: Cheong Ho Lim, M.D.

Department of Coloproctology, Yang Hospital, 1159 Cheonho-daero,

Gangdong-gu, Seoul 134-814, Korea

Tel: +82-2-480-8008, Fax: +82-2-480-8119

E-mail:chlim3164@naver.com

(c) 2012 The Korean Society of Coloproctology

This is an open-access article distributed under the terms of the Creative Commons Attribution NonCommercial License (http://creativecommons.org/licenses/by-nc/3.0) which permits unrestricted non-

commercial use, distribution, and reproduction in any medium, provided the original work is properly cited. and keeping the function of anal sphincter are the goals when treating fistulae. A concomitant anal fistulotomy and incision and drainage of the anorectal suppuration are often voided for fear of irreversibly impairing anal continence [6]. However, failure to identify and treat the associated anal fistula destined the patient to recurrent anal suppurative disease.

The authors have taken an aggressive approach to performing incision and drainage in conjunction with a fistulotomy. That approach uses a drainage seton for the ischiorectal abscess at the time of initial presentation. The purpose of this study is to assess the outcome of management of a fistula with or without an ischiorectal abscess by using the method of staged drainage seton.

\section{METHODS}

This paper represents a retrospective review of 53 patients who underwent treatment for an anal fistula with or without an ischiorectal abscess by one same surgeon from January 2010 to Decem- 
ber 2011. Patients with a supralevator extension of the abscess or an associated fistula tract, those with a Crohn's fistula or tuberculous. fistula, those who did not have an internal opening (IO), and those lost during the follow-up check were excluded from the study. The fistulas were classified according to Parks classification, and in this study, all of the horseshoe extensions were accompanied by a transsphincteric-type fistula. The authors handled the horseshoe-type fistula separately from the transsphincteric-type fistula because of the appreciable differences in the consequences of treatment.

Throughout this paper, a transsphincteric fistula means a transsphincteric-type fistula without an accompanying horseshoe extension. Additionally, a 'fistulous abscess' refers to anorectal suppuration for which a fistula tract and IO were definitely found and

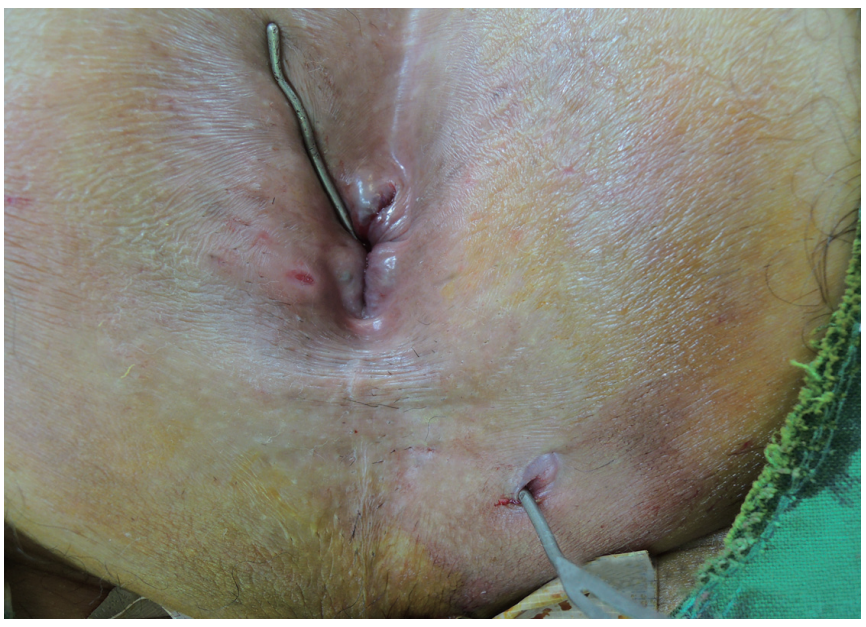

Fig. 1. A metallic probe was inserted gently from the external to the internal opening of the fistula. Meticulous care should be taken not to make an iatrogenic tract or opening because of forceful insertion.

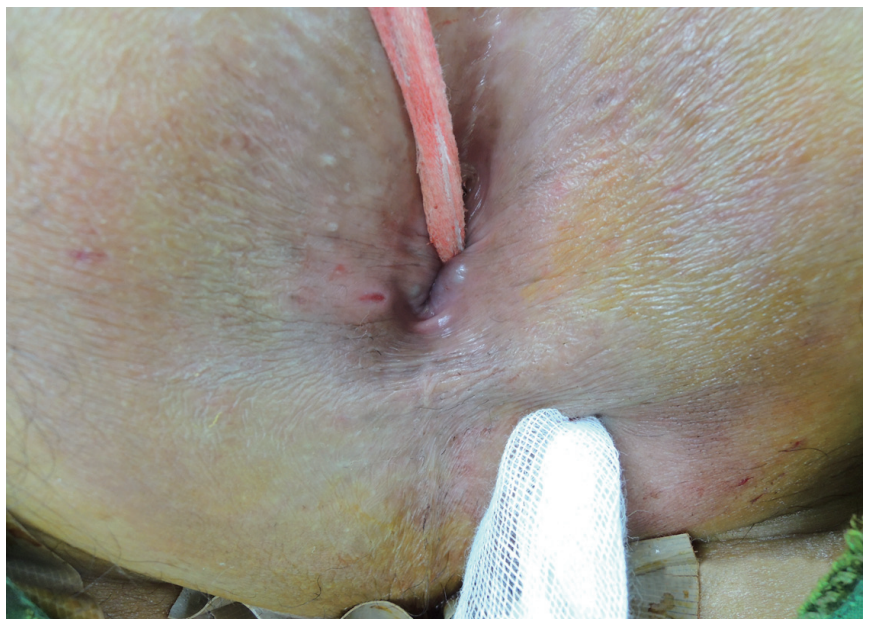

Fig. 2. A gauze was inserted through the fistula tract for curettage. Epithelization of the fistula tract can be destroyed by moving the gauze back and forth several times. for which a 'combined operation, the set up of a drainage seton with deliberate closure of the internal fistula opening and specific repair of the internal sphincter, resulting in a rerouting of the seton through the intersphincteric space, was used.

Special attention was paid to evaluating the rates of recurrence and anal continence. Operative and office records were reviewed, and follow-up data were obtained by clinical evaluation and telephone interview. Recurrence during the follow-up period was defined in this study as the growth of secondary anorectal sepsis or discharge on the same spot or elsewhere. Incontinence was defined as three or more episodes per week of inability to voluntarily control flatus, liquid, or solid stool. Data collected included age, sex, symptoms, IO location with or without horseshoe extension, presence or absence of abscess, closure of the IO or not, relationship between the type of fistula and recurrence, relationship between the type of fistula and the period of treatment, the relationship between recurrence and the presence of an abscess, the relationship between IO closure and recurrence, the relationship between the period of seton change and recurrence, and reported continence for flatus, liquid stool, and solid stool. The period of follow-up was from 8 to 31 months, with a median of 20 months. Currently, we are not considering comparing our technique with other aggressive nonsphincter-sparing surgical techniques. That is beyond the scope of our work.

Statistical analyses were conducted using the SPSS ver. 12.0 (SPSS Inc., Chicago, IL, USA). For continuous variables, the Student's ttest was used for comparative analyses. Statistical significance was defined as $\mathrm{P}<0.05$ at the $95 \%$ confidence level.

\section{Operative technique}

Under the saddle block with $0.5 \%$ bupivacaine, the patient was placed in a prone jack-knife position. Both buttocks were separated and fixed with adhesive tape for good operative field, and

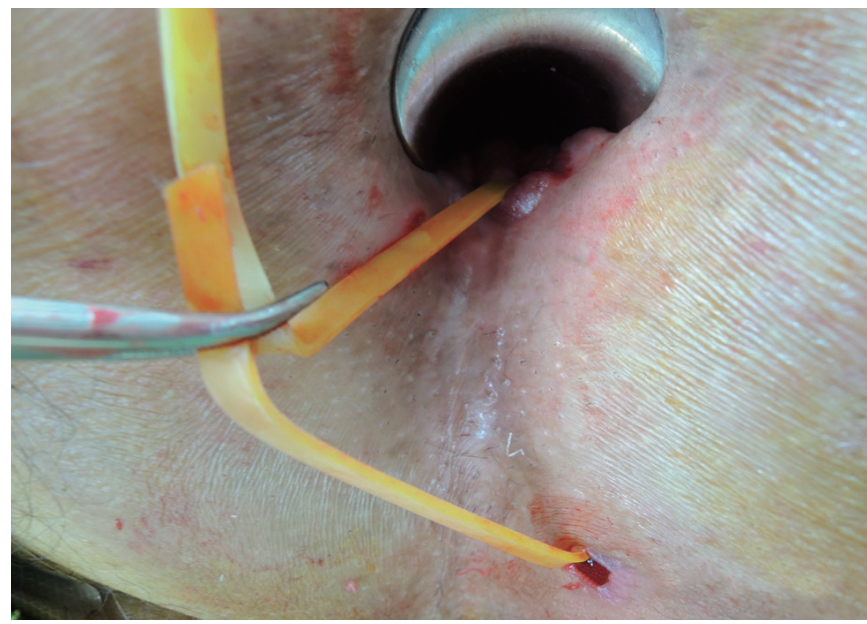

Fig. 3. A rubber band was inserted through the fistula tract as a seton. In this procedure, a 5-mm rubber band was used. 
the presence of a fistula or concomitant abscess was checked while applying betadine sponge around the area. For the case of a fistula only, a drainage seton was inserted from the external opening to the IO through a metallic probe after gauze curettage of the fistula tract (Figs. 1 and 2). A rubber band with a 5-mm width was used as the seton (Fig. 3). If the muscle contained along the seton was bulky, a partial internal sphincterotomy was performed to reroute the seton (Fig. 4). Then, the IO of the fistula was closed with concomitant internal anal sphincter repair, resulting in a rerouting of the seton through the intersphincteric space (combined operation), by using absorbable suture material, 4-0 Surgisorb (Samyang, Seoul, Korea). The internal muscle defect and the intersphincteric plane were closed with several interrupted sutures, at least two

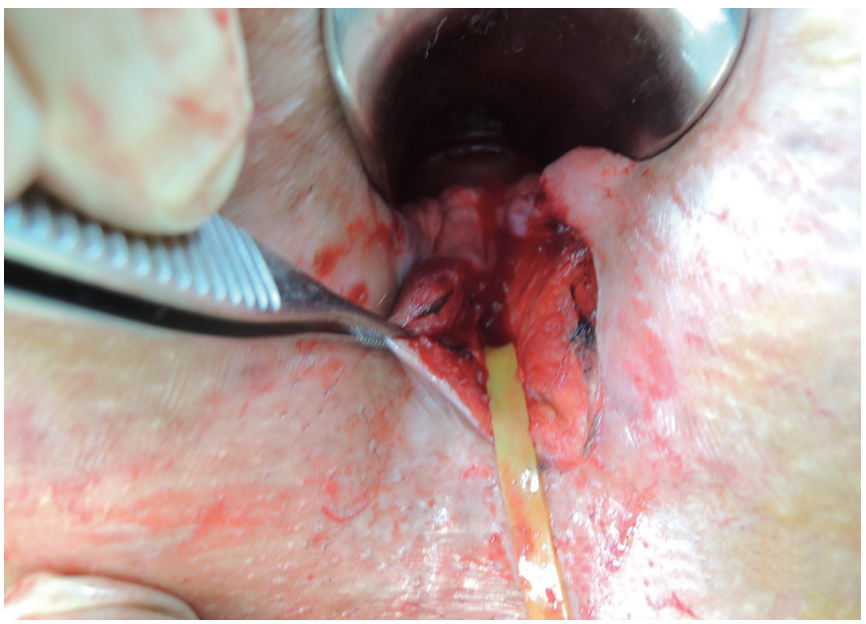

Fig. 4. A partial internal sphincterotomy from the internal to the external opening was performed.

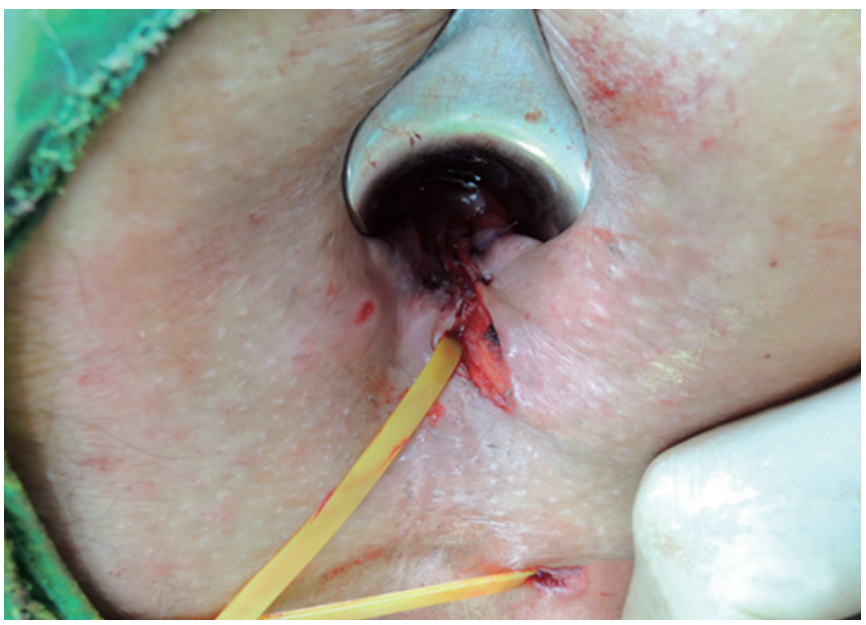

Fig. 5. The incised internal opening and the internal anal sphincter were repaired with interrupt suture at least two layers of absorbable suture material (4-0 Surgisorb). With this procedure, re-routing of the fistula through the intersphincteric plane was accomplished. layers (Figs. 5 and 6). The seton was tied loosely for drainage (Fig. 7). For the fistulous abscess, drainage was performed via a radial stab incision made close to the anal verge. The rubber band was inserted through the incised wound to the IO, which allowed all necrotic debris to be removed. As mentioned previously for the case of a fistula only, under similar circumstances, a combined operation was added. The seton was knotted loosely for drainage. Anal packing was not used for all patients for their convenience.

Cefradine (1.0 g, Cephradine, Yuhan, Seoul, Korea) was used intravenously 30 minutes before surgery, and Cefradine and Amikin

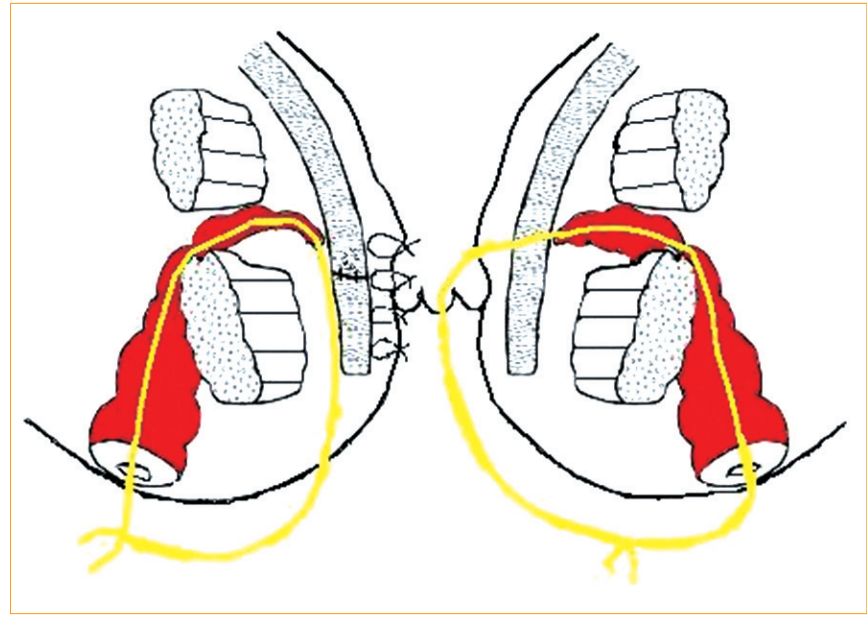

Fig. 6. Schematic view of the rerouting procedure. The drawing on the right shows insertion of the seton through the transsphincteric fistulous tract, and that on the left shows completion of the rerouting procedure with repair of the incised internal anal sphincter and closure of the internal opening.

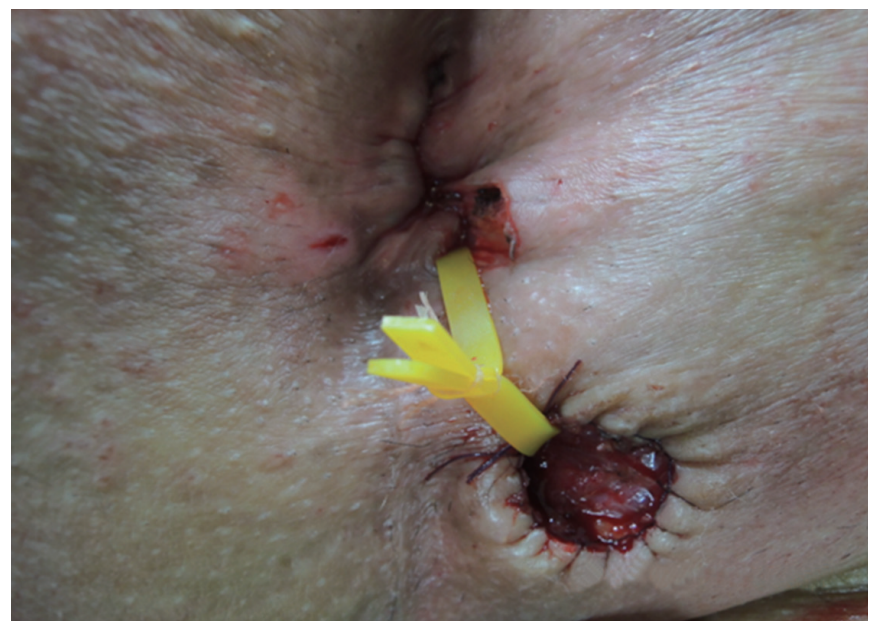

Fig. 7. Completion of the operation. The seton was tied loosely for drainage. The external opening of the fistula was marsualized with absorbable suture material. 
(3.0 g and $2.0 \mathrm{~g}$, respectively, Amikacin, Boryung Pharm, Seoul, Korea) and Flasinyl (750 mg, Metronidazole, CJ Pharm, Seoul, Korea) were administered for 3 days in divided doses postoperatively. Pain was controlled with patient-controlled analgesia, which was a mixture with 5 ampules of Tarasyn (Ketorolac Tromethamine, Dongkuk Pharm, Seoul, Korea). During the follow-up in the office, after a good while, once the amount of discharge through the seton was decreased markedly, the seton was changed to 3-0 nylon. Treatment was completed when there were no signs of discharge at which time the 3-0 nylon was removed. To keep track of patients' condition, telephone interviews were conducted.

\section{RESULTS}

Out of 53 patients, 44 were male (83\%) and 9 were female $(17 \%$, $\mathrm{P}=0.000$ ) (Table 1 ). They averaged 39.4 years old, with the largest number of patients having ages between 31 to 40 years $(13,24.5 \%$; $\mathrm{P}=0.000)$. The most common symptoms included tender swelling (33 patients, $62.3 \%$ ), discharge, (16 patients, $30.2 \%$ ), and pain (4 patients, $7.5 \%$ ). IOs were positioned most frequently at 6 and 12 oclock (45.2\% each, $\mathrm{P}=0.000$ ); multiple locations, 6,8 , and 12 oclock, were found in one case.

The transsphincteric-type fistula was the most frequent $(\mathrm{P}=$ 0.000 ), being seen in 36 cases $(67.9 \%)$, and the horseshoe type was found in 7 cases (13.2\%) (Table 2). Thirty-nine (73.6\%) pa-

Table 1. Characteristics of patients $(n=53)$

\begin{tabular}{lc}
\hline Variable & Value \\
\hline Gender & $P=0.000$ \\
Male & 44 \\
Female & 9 \\
Age (yr) & \\
$10-20$ & 5 \\
$21-30$ & 10 \\
$31-40$ & 13 \\
$41-50$ & 12 \\
$51-60$ & 10 \\
$61-70$ & 3 \\
Symptoms & \\
Tender swelling & 33 \\
Discharge & 16 \\
Pain & 4 \\
Location of internal opening (o'clock) & \\
5 & 24 \\
6 & 24 \\
12 & 2 \\
6,12 & \\
\hline
\end{tabular}

tients had a fistula concomitant with abscess (fistulous abscess), and the number of patients having a fistula without abscess was $14(26.4 \%, \mathrm{P}=0.000)$. Among the 39 fistulous abscess cases, the most common was the transsphincteric type with ischiorectal abscess ( 28 cases, $71.8 \%$; $\mathrm{P}=0.000$ ).

Twenty-two (41.5\%) patients were treated with seton alone, and 31 patients $(58.5 \%)$ were treated with combined operation $(\mathrm{P}=$ 0.000). For each type of fistula, 9 out of 10 patients (90\%) were treated with seton alone for the intersphincteric-type fistula, but for the transsphincteric-type fistula, 25 out of 36 patients (69.4\%) and for the horseshoe-type fistula, 5 out of 7 patients (71.4\%) underwent a combined operation. Among the 28 patients with a transsphincteric-type fistula accompanied by an abscess, the ratio of combined operation to seton alone was 20 to 8 (71.4\% : 28.6\%). For the 8 patients having only a fistula, the ratio was 5 to $3(62.5 \%$ : $37.5 \%$ ), and for the 6 patients with a horseshoe-type fistula accompanied by an abscess, a combined operation was performed in 4 patients $(66.7 \%)$.

Overall recurrence after surgical treatment amounted to 7 out of 53 patients (13.2\%), but when the horseshoe type was considered separately (57.1\%, 4 out of 7 patients), the recurrence rate was $6.5 \%$ (3 out of 46 patients), all in the transsphincteric-type fistula ( $\mathrm{P}=$ 0.000). Recurrence occurred in 6 patients with a fistulous abscess and in 1 patient with a fistula only. Among patients with recurrence, 3 were treated with seton alone $(42.9 \%, 2$ with a transsphincterictype fistula and 1 with a horseshoe-type fistula), and 4 patients were treated with a combined operation $(57.1 \%, 1$ with a transsphincteric-type fistula and 3 with a horseshoe-type fistula). Two out of 53 patients (3.8\%) were observed as having incontinence,

Table 2. Relationships among the type of fistula, presence of abscess, combined treatment and the rate of recurrence

\begin{tabular}{cccc}
\hline & $\begin{array}{c}\text { Intersphincteric } \\
\text { fistula } \\
(\mathrm{n}=10)\end{array}$ & $\begin{array}{c}\text { Transsphinc- } \\
\text { teric type } \\
(\mathrm{n}=36)\end{array}$ & $\begin{array}{c}\text { Horseshoe } \\
\text { extension } \\
(\mathrm{n}=7)\end{array}$ \\
\hline Presence of abscess (yes) & 5 & 28 & 6 \\
Combined operation (yes) & 1 & 20 & 4 \\
Recurrence & 0 & 1 & 2 \\
Incontinence & 0 & 0 & 0 \\
Combined operation (no) & 4 & 8 & 2 \\
Recurrence & 0 & 2 & 1 \\
\hline Incontinence & 0 & 0 & 1 \\
Presence of abscess (no) & 5 & 8 & 1 \\
Combined operation (yes) & 0 & 5 & 1 \\
Recurrence & 0 & 0 & 1 \\
Incontinence & 0 & 0 & 1 \\
Combined operation (no) & 5 & 3 & 0 \\
Recurrence & 0 & 0 & 0 \\
Incontinence & 0 & 0 & 0 \\
\hline
\end{tabular}


Table 3. Periods from the date of operation to seton change with 3-0 nylon, from the date of seton change to complete removal of 3-0 nylon, and from the date of operation to complete removal of 3-0 nylon, and corresponding numbers of patients

\begin{tabular}{lccc}
\hline Period (day) & $\begin{array}{c}\text { Operation } \\
\text { to seton } \\
\text { change }\end{array}$ & $\begin{array}{c}\text { Seton change } \\
\text { to complete } \\
\text { removal }\end{array}$ & $\begin{array}{c}\text { Operation } \\
\text { to complete } \\
\text { removal }\end{array}$ \\
\hline $3-5$ & 4 & 1 & \\
$6-10$ & 10 & 0 & 1 \\
$11-15$ & 14 & 6 & 1 \\
$16-20$ & 7 & 2 & 5 \\
$21-25$ & 5 & 5 & 3 \\
$26-30$ & 4 & 18 & 7 \\
$31-35$ & 7 & 7 & 6 \\
$36-40$ & 2 & 6 & 8 \\
$41-45$ & & 2 & 11 \\
$46-50$ & & 0 & 6 \\
$51-60$ & & 1 & 1 \\
$61-70$ & 53 & 49 & 49 \\
$71-$ & $15 \pm 9.76$ & $28 \pm 11.40$ & $46 \pm 14.70$ \\
\hline Total & & 1 & \\
Median \pm SD (day) & & & \\
\hline
\end{tabular}

Values are presented as no. of patients unless otherwise indicated. $\mathrm{SD}$, standard deviation.

only gas incontinence, all with a horseshoe-type fistula.

The time from surgery $(\mathrm{p} 1)$ to the change to $3-0$ nylon (p2) was 3 to 38 days (median, 15 days) (Table 3 ), and the time from $\mathrm{p} 2$ to removal of the 3-0 nylon (p3) was 5 to 69 days (median, 28 days). The time from surgery (p1) to removal of the nylon entirely (p3) was 18 to 104 days (median, 46 days). In cases of intersphincterictype fistulae, the median values for $\mathrm{p} 1, \mathrm{p} 2$, and $\mathrm{p} 3$ were 13.5 days, 27.8 days, and 40 days, respectively (Table 4 ). The corresponding median values were 15 days, 28 days, and 46 days for transsphincteric-type fistulae and 20 days, 28 days, and 49.5 days for horseshoe-type fistulae.

\section{DISCUSSION}

The aim of treatment of an anal fistula is to eradicate the condition without disturbing continence. Various techniques, such as the fistulotomy, fistulectomy and advancement flap procedure, have been proposed [7]. Current surgical techniques for treating anal fistulas are based on three main principles: identification of the tract and the IO, excision of the fistula tract, and preservation of anal sphincter function [8]. Seton application is one operative method that preserves the function of the sphincter muscle and reduces incontinence when compared with other methods. Other treatments include chemical, drainage and cutting seton, depend-
Table 4. Median periods, according to the type of fistula, from the date of operation to seton change with 3-0 nylon, from the date of seton change to complete removal of 3-0 nylon, and from the date of operation to complete removal of 3-0 nylon

\begin{tabular}{lccc}
\hline Fistula type & $\begin{array}{c}\text { Operation } \\
\text { to seton change } \\
\text { (day) }\end{array}$ & $\begin{array}{c}\text { Seton change } \\
\text { to complete } \\
\text { removal (day) }\end{array}$ & $\begin{array}{c}\text { Operation } \\
\text { to complete } \\
\text { removal (day) }\end{array}$ \\
\hline Intersphincteric & 13.5 & 27.8 & 40 \\
Transsphincteric & 15 & 28 & 46 \\
Horseshoe & 20 & 28 & 49.5 \\
P-value & 0.673 & 0.826 & 0.465 \\
\hline
\end{tabular}

ing on the purpose. The cutting seton treatment for fistulae has been used for centuries and is still common. The purported advantages of the technique include its ability to drain the region while preventing recurrent abscess and the promotion of fibrosis around the seton during slow division of the sphincter. In theory, fibrosis prevents retraction of the sphincter behind the seton's advance. However, the incontinence rates after treatment of transsphincteric, suprasphincteric and extrasphincteric fistulae were reported as $20.5 \%, 67 \%$, and $37 \%$, respectively [7], but the real incidence of fecal incontinence has been shown to be underestimated in medical charts [9]. On the other hand, the use of a loose seton in the treatment of anal fistulae is well known to decrease the incidence of incontinence (17\%) [10,11], but the recurrence rate of the fistula or suppuration was reported as $19.5 \%$ in cases of transsphincteric fistulae [12], with recurrence being observed in 7, 11, and 15 among 20 patients at 6,15 , and 60 months, respectively, after seton removal [13].

For the treatment of a fistula or a fistulous abscess, in this study, the authors used drainage seton and removed it in a staged way, which means that the rubber band during surgery as the seton was changed with 3-0 nylon after a considerable interval that depended on the amount of discharge from the fistula tract. This procedure is referred to as the 'staged drainage seton' in this paper. This process can decrease the size of the caliber of the fistula tract gradually via formation of granulation tissue around the nylon, and it has a role in drainage until complete healing of the fistula tract. After discharge from the fistula tract has been minimized or disappears, the nylon is removed. Seton alone or combined surgery (seton application, rerouting, IO closure, internal sphincter repair) for treating a fistula or a fistulous abscess was used according to the bulkiness of the muscle involved within the seton. In $90 \%$ of intersphincteric-type fistulae, the seton was applied without a combined operation. Compared with the commonly-used loose seton method [14], this staged way can minimize the possibility of incontinence (3.8\% vs. $17 \%)$ and the recurrence rate of the fistula ( $6.5 \%$ vs. 19.5 to $75 \%$ ) $[12,13]$. In this study, the recurrence (persistence) rate varied with the type of fistula, but there was no statistically significance relation between the presence of abscess/type of operation and recurrence $(\mathrm{P}=0.44$ and 0.94$)$. The 
rubber seton was removed from one patient on the third postoperative day regardless of the decrease in the drainage fluid due to marked discomfort cause by the seton (transsphincteric-type fistula with abscess). The patient kept 3-0 nylon for 60 days, and the entire seton was removed on the 63rd day. The patient showed no sign of recurrence or incontinence. Another patient who changed from the rubber seton to 3-0 nylon 35 days after surgery had the seton completely removed after 104 days because he didn't appear on the designated date. For four patients with recurrence during follow-up, the 3-0 nylon was removed during the reoperation. For each type of fistula, no statistically significant relation between the seton duration ( $1, \mathrm{p} 2, \mathrm{p} 3)$ and recurrence was observed $(\mathrm{P}=$ 0.51). Both fistulae and abscesses recurred within 160 days after surgery for all seven patients. Among them, one patient with a transsphincteric-type fistula recurrence fully recovered after three consecutive identical surgical operations, three with a subcutaneous-type fistula recurrence underwent a fistulotomy (lay open), one with a transsphincteric-type fistula recurrence underwent a coring out, one patient was treated with incision and drainage at another clinic, and one patient whose recurrence was recognized through a telephone interview still has not visited our clinic.

Incontinence occurred in only 2 out of 53 patients (3.8\%) during the postoperative follow-up period ( 8 to 31 months; median, $20 \pm$ 5.78 months). The two patients, suffering from horseshoe-type fistulae, showed gas incontinence only. Among the two, one patient underwent a sphincterotomy (lay open) because the patient's abscess had recurred three times. The overall recurrence rate in this study was $13.2 \%$, and the incontinence rate was $3.8 \%$. The results cannot be compared directly with those of other studies because of lack of similar reports, but considering the exceptionably high recurrence rate for horseshoe-type fistulae (57.1\%), the recurrence rate of $6.5 \%$ for transsphincteric fistulae can be reasonably accepted. These results can be compared with those in references [6-9, 12-18], which reported recurrence rates of 35 to $95 \%$ and incontinence rates of 5.9 to $39.4 \%$.

In conculsion, the authors' experience supports the fact that the use of a staged drainage seton for the treatment of fistulae and associated ischiorectal abscesses can result in a lower incidence of recurrence and an acceptable incontinence rate. Statistically, the recurrence rate is not related with the type of operation or the presence of concomitant abscess, or but with the type of fistula.

\section{CONFLICT OF INTEREST}

No potential conflict of interest relevant to this article was reported.

\section{REFERENCES}

1. Kennedy HL, Zegarra JP. Fistulotomy without external sphincter division for high anal fistulae. Br J Surg 1990;77:898-901.

2. Jones IT, Fazio VW, Jagelman DG. The use of transanal rectal advancement flaps in the management of fistulas involving the anorectum. Dis Colon Rectum 1987;30:919-23.

3. Wedell J, Meier zu Eissen P, Banzhaf G, Kleine L. Sliding flap advancement for the treatment of high level fistulae. Br J Surg 1987; 74:390-1.

4. Reznick RK, Bailey HR. Closure of the internal opening for treatment of complex fistula-in-ano. Dis Colon Rectum 1988;31:116-8.

5. Athanasiadis S, Helmes C, Yazigi R, Kohler A. The direct closure of the internal fistula opening without advancement flap for transsphincteric fistulas-in-ano. Dis Colon Rectum 2004;47:1174-80.

6. Schouten WR, van Vroonhoven TJ, van Berlo CL. Primary partial internal sphincterectomy in the treatment of anorectal abscess. Neth J Surg 1987;39:43-5.

7. Ritchie RD, Sackier JM, Hodde JP. Incontinence rates after cutting seton treatment for anal fistula. Colorectal Dis 2009;11:564-71.

8. Cox SW, Senagore AJ, Luchtefeld MA, Mazier WP. Outcome after incision and drainage with fistulotomy for ischiorectal abscess. Am Surg 1997;63:686-9.

9. Enck P, Bielefeldt K, Rathmann W, Purrmann J, Tschope D, Erckenbrecht JF. Epidemiology of faecal incontinence in selected patient groups. Int J Colorectal Dis 1991;6:143-6.

10. Parks AG, Stitz RW. The treatment of high fistula-in-ano. Dis Colon Rectum 1976;19:487-99.

11. Thomson JP, Ross AH. Can the external anal sphincter be preserved in the treatment of trans-sphincteric fistula-in-ano? Int J Colorectal Dis 1989;4:247-50.

12. Eitan A, Koliada M, Bickel A. The use of the loose seton technique as a definitive treatment for recurrent and persistent high transsphincteric anal fistulas: a long-term outcome. J Gastrointest Surg 2009;13:1116-9.

13. Buchanan GN, Owen HA, Torkington J, Lunniss PJ, Nicholls RJ, Cohen CR. Long-term outcome following loose-seton technique for external sphincter preservation in complex anal fistula. Br J Surg 2004;91:476-80.

14. Lee YY, Choi SK, Kim SJ, Lee KY, Hur YS, Ahn SI, et al. The clinical effect of sphincter-preserving modified loose seton technique in complex anal fistula. J Korean Soc Coloproctol 2002;18:156-62.

15. Ramanujam PS, Prasad ML, Abcarian H, Tan AB. Perianal abscesses and fistulas: a study of 1023 patients. Dis Colon Rectum 1984;27:593-7.

16. Scoma JA, Salvati EP, Rubin RJ. Incidence of fistulas subsequent to anal abscesses. Dis Colon Rectum 1974;17:357-9.

17. La C, Wang J, On GB. Anorectal suppuration: a review of 606 cases. Southeast Asian J Surg 1983;6:22-6.

18. Vasilevsky CA, Gordon PH. The incidence of recurrent abscesses or fistula-in-ano following anorectal suppuration. Dis Colon Rectum 1984;27:126-30. 